\title{
The Effect of Habitual Exercise on Respiratory- Muscle Function in Older Adults
}

\author{
Mark L. Watsford, Aron J. Murphy, \\ Matthew J. Pine, and Aaron J. Coutts
}

Older adults' participation in habitual exercise might be affected by alterations to respiratory mechanics such as decreased respiratory-muscle strength. This reduction can cause a decrease in efficiency of the ventilatory pump, potentially compromising exercise participation. This research examined the role of habitual exercise in respiratory-muscle function and the associated implications for exercise performance. Seventy-two healthy older adults ( 36 men, 64.9 \pm 8.6 years, $177.2 \pm 8.4 \mathrm{~cm}, 82.5 \pm 11.9 \mathrm{~kg} ; 36$ women, $64.9 \pm 9.5$ years, $161.7 \pm 6.4$ $\mathrm{cm}, 61.6 \pm 9.2 \mathrm{~kg}$ ) undertook respiratory-function and walking-performance tests. Active men and women achieved higher scores than their inactive counterparts for all tests except spirometry, where no differences were evident. The results indicate that a significant amount of the elevated fitness level might be accounted for by increased endurance capacity of the inspiratory muscles. Inactive older individuals might be at risk for inadequate respiratory-muscle strength, so interventions should be considered.

Key Words: elderly, respiratory function, age-related decline, exercise intensity

The median age of the Australian and, indeed, the world's population is increasing (ABS, 2001). Aging has been shown to affect many areas of physiology (Åstrand, Åstrand, Hallback, \& Kilbom, 1973), which can lead to a decrease in quality of life (Brown, 1992). Age-related sarcopenia is a confounding factor of this decrease, affecting coordination, confidence, and the ability to undertake activities of daily living (ADL; Evans, 1995). The incidence of sarcopenia might be greater in women (Plonczynski, 2003) and might also affect the respiratory muscles (RM; Janssens, Pache, \& Nicod, 1999). Evidence has suggested that the RM might be a limiting factor to exercise performance in both healthy and sedentary subjects (Boutellier, Büchel, Kundert, \& Spengler, 1992; Boutellier \& Piwko, 1991; Rohrbach, Perret, Kayser, Boutellier, \& Spengler, 2003). Such a reduction in function potentially manifests in decreased physiological capacity (Buskirk \&

The authors are with the School of Leisure, Sport and Tourism, University of Technology, Sydney, Lindfield, NSW 2070 Australia. 
Hodgson, 1987; Janssens et al.; Poulin, Cunningham, Paterson, Kowalchuk, \& Smith, 1993).

Research examining the role of gender and exercise participation in RM function is limited. Available research has not addressed the practical applications of the relationship between physical activity and RM strength and endurance or examined the possibility that decreased RM capacity might have a negative effect on exercise performance in the older population. This issue might be of critical importance in the older population, because older adults are reportedly less likely to participate in regular exercise to stimulate a training effect (Roubenoff, 2000). The purpose of our study was to examine the role of habitual exercise on RM function and the implications for exercise performance. We also investigated whether participation in regular exercise by older adults was of sufficient intensity to slow or even reverse the age-related decay in RM strength.

\section{Methods}

\section{PARTICIPANTS}

Seventy-two healthy older adults (36 men, $64.9 \pm 8.6$ years, $177.2 \pm 8.4 \mathrm{~cm}, 82.5 \pm$ $11.9 \mathrm{~kg}$; 36 women, $64.9 \pm 9.5$ years, $161.7 \pm 6.4 \mathrm{~cm}, 61.6 \pm 9.2 \mathrm{~kg}$ ) were recruited from the local community and provided their informed consent to participate in the study. Each participant completed a modified medical- and physical-activityhistory questionnaire (Healthscreen, Human Kinetics). Participants who performed a minimum of three exercise sessions per week or were involved in at least $5 \mathrm{hr}$ per week of moderate-intensity activity were classified as being active ( $n=18$ men, $n=18$ women; Tanaka et al., 1997; Table 1). The exercise typically consisted of walking at a moderate intensity, but several participants reported regular participation in cycling, running, resistance training, and numerous court sports (tennis, squash). The nonactive group consisted of individuals who performed two or fewer

Table 1 Participant Characteristics for Gender and Physical Level, $M \pm S D$

\begin{tabular}{|c|c|c|c|c|}
\hline & \multicolumn{2}{|c|}{ Men } & \multicolumn{2}{|c|}{ Women } \\
\hline & $\begin{array}{c}\text { Active, } \\
n=18\end{array}$ & $\begin{array}{c}\text { Nonactive, } \\
n=18\end{array}$ & $\begin{array}{c}\text { Active, } \\
n=18\end{array}$ & $\begin{array}{c}\text { Nonactive } \\
n=18\end{array}$ \\
\hline Age & $64.6 \pm 8.8$ & $65.2 \pm 8.7$ & $64.8 \pm 8.8$ & $65.2 \pm 10.3$ \\
\hline Height $(\mathrm{cm})$ & $176.9 \pm 8.3$ & $177.5 \pm 8.7$ & $163.3 \pm 6.1$ & $160.0 \pm 6.3$ \\
\hline Body mass $(\mathrm{kg})$ & $79.6 \pm 12.7$ & $85.5 \pm 10.7$ & $59.5 \pm 8.4$ & $63.8 \pm 9.8$ \\
\hline Weekly exercise sessions & $5.5 \pm 2.9$ & $1.9 \pm 1.4^{*}$ & $5.6 \pm 2.7$ & $1.3 \pm 0.8^{*}$ \\
\hline
\end{tabular}

$* p<.05$. 
moderate-intensity exercise sessions per week. There was no significant difference between active and nonactive participants for the number of medical conditions affecting exercise participation or the number of medications for these ailments. The participants were required to attend the laboratory on two separate occasions, with physiological tests including spirometry testing, assessment of RM strength, an inspiratory-muscle-endurance (IME) test, and a 1.6-km-walk test. All tests were implemented by one trained technician, who offered strong verbal encouragement during each of the tests. The research was approved by the Human Research Ethics Committee at the University of Technology, Sydney.

\section{SPIROMETRY}

Forced vital capacity (FVC), forced expiratory volume in $1 \mathrm{~s}\left(\mathrm{FEV}_{1}\right)$, peak expiratory flow (PEF), and maximum voluntary ventilation (MVV) were assessed on a spirometer (Spiro 501, Bosch, Germany). All spirometry procedures were conducted using standards set by the Thoracic Society of Australia and New Zealand. Standard predictive equations from the European Coal and Steel Community (Quanjer et al., 1993) for adults were used, with results reported as percentage of predicted value, thus taking height and age into consideration. These procedures required the performance of at least three technically acceptable trials, with the largest score within $\pm 5 \%$ variation accepted for analysis, thus ensuring reliability of the results (Enright, Johnson, Connett, Voelker, \& Buist, 1991).

\section{RESPIRATORY MUSCLE STRENGTH}

Maximal inspiratory pressure $\left(\mathrm{P}_{\text {Imax }}\right)$ and maximal expiratory pressure $\left(\mathrm{P}_{\text {Emax }}\right)$ were measured using a portable mouth pressure gauge (Spirovis, Cosmed, Italy). The Spirovis consists of an occluded airway that contains a 2-mm-diameter leak to prevent artificially elevated pressures being developed by the muscles of the mouth while the glottis is closed. $\mathrm{P}_{\text {Imax }}$ was performed from residual volume, and $\mathrm{P}_{\text {Emax }}$ was performed from total lung capacity (Clanton \& Diaz, 1995). Participants remained in a seated position with a nose clip in place and were required to hold the sides of their mouths during $\mathrm{P}_{\text {Emax }}$ assessment to prevent air leaking out the side of the mouthpiece. They were required to breathe through the mouthpiece, attempting to "inhale/exhale the air as fast and hard as possible." The maximum pressure maintained for $1 \mathrm{~s}$ was recorded. All participants performed a minimum of three trials until several technically correct efforts were made. The highest value within $\pm 5 \%$ variability was recorded. The reliability of this procedure with healthy subjects was published previously (Larson \& Kim, 1987).

\section{INSPIRATORY MUSCLE ENDURANCE}

The endurance of the inspiratory muscles was assessed using the Powerlung ${ }^{\text {TM }}$ RMtraining device (Powerlung, USA). The Powerlung is a threshold-loading device consisting of a rigid plastic tube housing two rubber plungers, each held in place 
by a spring. In order to produce significant airflow, the participant must generate respiratory pressures that overcome the threshold pressure $\left(\mathrm{P}_{\mathrm{TH}}\right)$, causing the spring to compress and the plunger to lift off its port. Although the Powerlung is able to place resistance on both the inspiratory and the expiratory muscles, the expiratory port was sealed in order to conduct a more specific examination of IME. Adjusting the inspiratory-resistance control of the Powerlung places more tension on the spring, increasing the $\mathrm{P}_{\mathrm{TH}}$ that must be overcome with each inspiration. A U-tube manometer was constructed and a vacuum pump used to calibrate the arbitrary resistance settings on the Powerlung devices in centimeters of water $\left(\mathrm{cmH}_{2} \mathrm{O}\right)$. A regression analysis performed on the relationship between these calibrated values and the arbitrary levels indicated that the levels on each device create a $\mathrm{P}_{\mathrm{TH}}$ that increases in a linear fashion $\left(r^{2}=.99\right)$.

IME was measured using a 2-min incremental threshold-loading (ITL) test. The reliability and validity of this test has been documented, with strong test-retest reliability of .90 for maximal pressure maintained for a complete stage (Larson et al., 1999). In a seated position with a nose clip in place, each participant started the test at the same $\mathrm{P}_{\mathrm{TH}}\left(13 \mathrm{cmH}_{2} \mathrm{O}\right)$. The participants were instructed to correctly place the mouthpiece in the mouth before beginning inspiration and to make sure that this breath had completely finished before taking it out of the mouth for normal expiration. Breathing frequency was not constrained because it has been demonstrated to be unnecessary during ITL (Martyn, Moreno, Pare, \& Pardy, 1987). After inspiring against this resistance for $2 \mathrm{~min}$, the participants underwent a 2-min rest involving normal breathing and the $\mathrm{P}_{\mathrm{TH}}$ was then increased. Strong verbal encouragement was regularly given during the exercise periods. This process continued until the participant could no longer overcome the $\mathrm{P}_{\mathrm{TH}}$ and generate significant airflow. The maximum pressure sustained for a complete 2-min stage was recorded for analysis $\left(\mathrm{P}_{\mathrm{END}}\right)$.

\section{6-KM-WALK TEST}

To estimate $\mathrm{VO}_{2 \max }$ and investigate self-selected walking speed, a 1.6-km walk was conducted around a standard 400-m grass athletic oval. Participants were instructed to cover the distance "walking as fast as comfortably possible." The reliability of this test has been previously established $(r=.71-.97)$ among many age groups including the elderly ( $r=.88$; Kline et al., 1987; O'Hanley et al., 1987), and this test was selected because exertions of this intensity are ideal for older adults. Heart rate was recorded at the completion of the walk $\left(\mathrm{HR}_{\mathrm{w}}\right)$, along with time to complete the distance $\left(\mathrm{T}_{\mathrm{W}}\right)$. Average walking speed $\left(\mathrm{S}_{\mathrm{W}}\right)$ was calculated for analytical purposes. $\mathrm{VO}_{2 \max }$ can be reliably estimated from the $1.6-\mathrm{km}$ walking test, with the following equation to yield the least standard error $(0.325 \mathrm{~L} / \mathrm{min}$; Kline et al., 1987):

$$
\begin{gathered}
\mathrm{VO}_{2 \max }(\mathrm{L} / \mathrm{min})=6.9652+(0.0091 \times \text { body mass })-(0.0257 \times \text { age }) \\
+(0.5955 \times \text { gender })-(0.2240 \times \text { time })-(0.0115 \times \text { heart rate })
\end{gathered}
$$

Values for gender: female $=0$, male $=1$ 


\section{STATISTICAL ANALYSES}

Data analysis was conducted using Statistical Package for the Social Sciences (SPSS $\left.{ }^{\circ}\right)$ version 11.0. Descriptive statistics were calculated for all variables and are reported as $M \pm S D$. The data were divided into male and female subgroups and analyzed with a one-way ANOVA to determine the presence of any differences between active and nonactive participants. For all procedures, significance was accepted at an alpha level of .05. After the examination of such differences, Pearson's product-moment-correlation analysis was performed to examine the relationship between RM variables and exercise performance. The amount of variance that $\mathrm{P}_{\text {Imax }}, \mathrm{P}_{\text {Emax }}$, and $\mathrm{P}_{\mathrm{END}}$ contributed to predicted $\mathrm{VO}_{2 \max }$ was examined by calculating the $r^{2}$ value of the relationship.

\section{Results}

\section{PHYSICAL CHARACTERISTICS AND PULMONARY FUNCTION}

ANOVA revealed that active women displayed a lower BMI $(22.3 \pm 2.9$ vs. 24.9 $\pm 3.5 \mathrm{~kg} / \mathrm{m}^{2}, p=.02$ ) than did nonactive women. There was no difference in BMI between activity groups for the men $\left(25.4 \pm 2.9 \mathrm{vs} .27 .2 \pm 3.6 \mathrm{~kg} / \mathrm{m}^{2}, p=.10\right)$. There were also no differences for any of the relative spirometry variables between the active and nonactive men or women, despite a trend toward a higher FVC\% for active women $(116.0 \pm 12.5 \%$ vs. $107.6 \pm 14.8 \%, p=.08)$.

\section{RESPIRATORY-MUSCLE FUNCTION}

Differences in RM function were evident between activity levels for men. Active men yielded $\mathrm{P}_{\text {Imax }}$ and $\mathrm{P}_{\text {Emax }}$ scores that were $14 \%(p=.04)$ and $25 \%(p=.01)$ greater than those of the nonactive men, respectively. When compared with the nonactive group, active women displayed scores that were $28 \%$ greater for the $\mathrm{P}_{\text {Imax }}$ test $(p=.04)$. No differences were evident between groups for the $\mathrm{P}_{\text {Emax }}$ test for the women. Active men showed a higher $\mathrm{P}_{\mathrm{END}}$ than the nonactive men $(28 \%$, $p=.01)$. No differences, however, were revealed in $\mathrm{P}_{\mathrm{END}}$ between the active and nonactive women.

Individuals with larger body dimensions typically present greater RM strength (Enright, Kronmal, Manolio, Schenker, \& Hyatt, 1994). Accordingly, the RM strength and endurance tests were examined relative to body mass. Significant differences were evident between active and nonactive participants for both men and women for relative $\mathrm{P}_{\text {Imax }}\left(\mathrm{P}_{\text {Imax REL }}\right)$, relative $\mathrm{P}_{\text {Emax }}\left(\mathrm{P}_{\text {Emax REL }}\right)$, and relative $\mathrm{P}_{\text {END }}\left(\mathrm{P}_{\text {END REL }}\right.$; Table 2$)$, with correlation analysis between aerobic fitness and RM strength showing moderate, significant results (Table 3).

\section{PHYSICAL PERFORMANCE}

Participation in regular exercise led to several differences in performance for the 1.6-km walk. In comparison with the nonactive group, the active male participants 
Table 2 Maximum Pressures Developed for the Respiratory-Muscle-Strength and Incremental-Threshold-Loading Tests Expressed in Relative and Absolute Terms, $M \pm S D$

\begin{tabular}{|c|c|c|c|c|}
\hline & \multicolumn{2}{|c|}{ Men } & \multicolumn{2}{|c|}{ Women } \\
\hline & $\begin{array}{c}\text { Active, } \\
n=18\end{array}$ & $\begin{array}{c}\text { Nonactive, } \\
n=18\end{array}$ & $\begin{array}{c}\text { Active, } \\
n=18\end{array}$ & $\begin{array}{c}\text { Nonactive, } \\
n=18\end{array}$ \\
\hline $\mathrm{P}_{\operatorname{Imax} \mathrm{ABS}}\left(\mathrm{cmH}_{2} 0\right)$ & $98.3 \pm 16.1$ & $86.3 \pm 18.3^{*}$ & $66.9 \pm 23.0$ & $52.3 \pm 19.0 *$ \\
\hline $\mathrm{P}_{\text {Imax REL }}\left(\mathrm{cmH}_{2} 0 / \mathrm{kg}\right)$ & $1.26 \pm 0.27$ & $1.03 \pm 0.25^{*}$ & $1.13 \pm 0.39$ & $0.82 \pm 0.28^{*}$ \\
\hline $\mathrm{P}_{\text {Emax ABS }}\left(\mathrm{cmH}_{2} 0\right)$ & $140.2 \pm 20.9$ & $112.2 \pm 35.4^{*}$ & $83.9 \pm 30.8$ & $68.7 \pm 26.7$ \\
\hline$P_{\text {Emax REL }}\left(\mathrm{cmH}_{2} 0 / \mathrm{kg}\right)$ & $1.78 \pm 0.28$ & $1.34 \pm 0.47 *$ & $1.42 \pm 0.53$ & $0.78 \pm 0.29 *$ \\
\hline$P_{\text {END ABS }}\left(\mathrm{cmH}_{2} 0\right)$ & $88.0 \pm 14.8$ & $69.0 \pm 22.7 *$ & $62.5 \pm 24.7$ & $50.0 \pm 21.0$ \\
\hline$P_{\text {END REL }}\left(\mathrm{cmH}_{2} \mathrm{O} / \mathrm{kg}\right)$ & $1.12 \pm 0.21$ & $0.82 \pm 0.28 *$ & $1.07 \pm 0.45$ & $0.78 \pm 0.29 *$ \\
\hline
\end{tabular}

Note. $\mathrm{P}_{\text {Imax } \mathrm{ABS}}=$ absolute maximum inspiratory pressure; $\mathrm{cmH}_{2} 0=\mathrm{cm}$ water pressure; $\mathrm{P}_{\text {Imax REL }}=$ relative maximum inspiratory pressure; $\mathrm{P}_{\mathrm{Emax} \mathrm{ABS}}=$ absolute maximum expiratory pressure $; \mathrm{P}_{\text {Emax REL }}=$ relative maximum expiratory pressure $; \mathrm{P}_{\mathrm{END} \mathrm{ABS}}=$ absolute maximum pressure maintained for greatest complete 2-min stage during inspiratory-muscle-endurance (IME) test; $\mathrm{P}_{\text {END REL }}=$ relative maximum pressure maintained for greatest complete 2-min stage during IME test.

$* p<.05$.

Table 3 Pearson's Product-Moment Correlations for Men and Women

\begin{tabular}{|c|c|c|c|c|}
\hline & $\begin{array}{l}\text { Predicted } \\
\mathrm{VO}_{2 \max }\end{array}$ & $\mathrm{P}_{\text {Imax REL }}$ & $\mathrm{P}_{\text {Emax REL }}$ & $\mathrm{P}_{\text {END REL }}$ \\
\hline \multicolumn{5}{|l|}{ Men } \\
\hline predicted $\mathrm{VO}_{2 \max }$ & 1 & & & \\
\hline $\mathrm{P}_{\text {Imax REL }}$ & $.39 *$ & 1 & & \\
\hline $\mathrm{P}_{\text {Emax REL }}$ & $.50 *$ & $.73 *$ & 1 & \\
\hline $\mathrm{P}_{\text {END REL }}$ & $.58^{*}$ & $.70 *$ & $.58 *$ & 1 \\
\hline \multicolumn{5}{|l|}{ Women } \\
\hline predicted $\mathrm{VO}_{2 \max }$ & 1 & & & \\
\hline $\mathrm{P}_{\text {Imax REL }}$ & $.54 *$ & 1 & & \\
\hline $\mathrm{P}_{\text {Emax REL }}$ & $.59 *$ & $.86 *$ & 1 & \\
\hline $\mathrm{P}_{\text {END REL }}$ & $.68^{*}$ & $.85^{*}$ & $.79 *$ & 1 \\
\hline
\end{tabular}

Note. $\mathrm{P}_{\text {Imax REL }}=$ relative maximum inspiratory pressure; $\mathrm{P}_{\mathrm{Emax} R E L}=$ relative maximum expiratory pressure; $\mathrm{P}_{\mathrm{ENDREL}}=$ relative maximum pressure maintained for greatest complete 2-min stage during inspiratory-muscle-endurance test.

$* p<.05$. 
Table 4 Results From 1.6-km-Walk Test, $M \pm S D$

\begin{tabular}{|c|c|c|c|c|}
\hline & \multicolumn{2}{|c|}{ Men } & \multicolumn{2}{|c|}{ Women } \\
\hline & $\begin{array}{c}\text { Active } \\
n=18\end{array}$ & $\begin{array}{c}\text { Nonactive, } \\
n=18\end{array}$ & $\begin{array}{c}\text { Active } \\
n=18\end{array}$ & $\begin{array}{c}\text { Nonactive, } \\
n=18\end{array}$ \\
\hline 1.6-km-walk time (s) & $899 \pm 116$ & $1015 \pm 120^{*}$ & $989 \pm 164$ & $1118 \pm 169^{*}$ \\
\hline $\begin{array}{l}\text { Predicted } \mathrm{VO}_{2 \max } \\
\left(\mathrm{ml} \cdot \mathrm{kg}^{-1} \cdot \mathrm{min}^{-1}\right)\end{array}$ & $34.9 \pm 7.4$ & $28.7 \pm 7.8^{*}$ & $28.9 \pm 6.8$ & $21.3 \pm 7.5^{*}$ \\
\hline Heart rate (beats/min) & $107 \pm 20$ & $104 \pm 13$ & $114 \pm 22$ & $110 \pm 17$ \\
\hline $\begin{array}{l}\text { Average walking speed } \\
(\mathrm{km} / \mathrm{hr})\end{array}$ & $6.5 \pm 0.8$ & $5.7 \pm 0.6^{*}$ & $5.9 \pm 0.9$ & $5.3 \pm 0.8 *$ \\
\hline
\end{tabular}

$* p<.05$.

achieved higher predicted scores for $\mathrm{VO}_{2 \max }(18 \%, p=.02)$ and $\mathrm{S}_{\mathrm{W}}(12 \%, p=.01)$ and a reduced $\mathrm{T}_{\mathrm{W}}(-13 \%, p=.01)$. When compared with the nonactive group, the active female group showed significantly higher scores for the same variables $\left(\mathrm{VO}_{2 \max }[26 \%, p<.01], \mathrm{S}_{\mathrm{W}}[12 \%, p=.02], \mathrm{T}_{\mathrm{W}}[-13 \%, p=.03]\right)$. These results are presented in Table 4. Furthermore, there were no differences in $\mathrm{HR}_{\mathrm{w}}$ across any of the comparisons between the active and nonactive groups.

\section{Discussion}

\section{PHYSICAL CHARACTERISTICS AND RESPIRATORY FUNCTION}

There were no differences in BM between the activity groups for men or women, nor were there any differences for the spirometry results. Active men exhibited greater absolute and relative $\mathrm{P}_{\text {Imax }}\left(14 \%\right.$ and $22 \%$, respectively), $\mathrm{P}_{\text {Emax }}(25 \%$ and $33 \%$, respectively), and IME (28\% and $37 \%$, respectively) than did the nonactive men. Differences in RM function between the female activity groups were evident between $\mathrm{P}_{\text {Imax ABS }}(28 \%), \mathrm{P}_{\text {Imax REL }}(38 \%), \mathrm{P}_{\text {Emax REL }}(82 \%)$, and $\mathrm{P}_{\text {END REL }}(37 \%)$. These results for both the men and the women are consistent with previous research stating that physical training leads to enhanced RM function (Clanton, Dixon, Drake, \& Gadek, 1987; Robinson \& Kjeldgaard, 1982). In support of previous research, results from the present study imply that the self-selected amount and intensity of physical activity undertaken by this sample of active older men and women is sufficient to produce elevated RM strength (McConnell \& Copestake, 1999).

In the older population, intensity of exercise might be compromised by sarcopenia and a range of other factors including a decrease in neural activation, coordination, and psychological function (Evans, 1995). This decrease in intensity might lead to a decreased stimulus for the respiratory system during exercise, 
thus decreasing the relative loading encountered by the RM. The age-related decrease in chest-wall compliance acts to further decrease RM strength (Janssens et al., 1999). The ensuing decrease in physiological function can lead to further decreases in exercise participation, forming a "vicious cycle" of disuse (Berger, 1989), possibly manifesting in breathlessness during ADL. Respiratory sensations including breathlessness are related to ratings of perceived exertion (Robertson, 1982), such that an increased respiratory effort might compromise quality of life for older individuals.

Several authors have presented normative values for RM strength based on age (Chen \& Kuo, 1989; McConnell \& Copestake, 1999; Neder, Andreoni, Lerario, \& Nery, 1999), covering large age ranges. When comparing the results of the current study with these data, some interesting relationships are evident. The active men in the current study recorded a $\mathrm{P}_{\text {Emax }}$ similar to that of 31- to 45-year-old men (Chen \& Kuo) and 30- to 39-year-old men (Neder et al.; Table 2). These results highlight the role of exercise participation in maintaining RM function. Alternatively, specific RM training has been shown to significantly improve RM strength and endurance. An increase in these properties potentially delays or eliminates the onset of dyspnea, thus enabling participation in physical activity of varying intensities. The role of $\mathrm{RM}$ function in older adults requires further research.

\section{PHYSICAL PERFORMANCE}

Active men and women completed the $1.6-\mathrm{km}$ walk faster than their nonactive counterparts, resulting in a significantly greater predicted $\mathrm{VO}_{2 \max }(18 \%$ and $26 \%$ for men and women, respectively; Table 4). These differences are indicative of the importance of regular exercise participation at any age in the lifespan, especially for the performance of ADLs in the older population. When performance of such activities is compromised, quality of life is decreased. Elevated $\mathrm{VO}_{2 \max }$ values permit individuals to undertake ADLs at a lower percentage of maximum, thus expending less relative effort (Lamoureux, Sparrow, Murphy, \& Newton, 2002). Any energysparing mechanism is beneficial to older individuals, because sarcopenia typically affects muscle efficiency (Roubenoff, 2000).

As Table 3 shows, significant correlations were produced between $\mathrm{P}_{\text {END REL }}$ and predicted $\mathrm{VO}_{2 \max }(r=.58, p<.01, r=.68, p<.01$ for men and women, respectively) and accounted for $33 \%$ and $46 \%$ of the variance in predicted $\mathrm{VO}_{2 \max }$ for men and women, respectively. Correlations between predicted $\mathrm{VO}_{2 \max }$ and $\mathrm{P}_{\mathrm{Imax}}$ and $\mathrm{P}_{\text {Emax }}$ were significant, but the relationships were not as strong as the IME results (men $\mathrm{P}_{\text {Imax }}, r=.39$; women $\mathrm{P}_{\text {Imax }}, r=.54$; men $\mathrm{P}_{\text {Emax }}, r=.50$; women $\mathrm{P}_{\text {Emax }}, r=.59$ ). Previously, body dimensions have been used with varying levels of success in an attempt to predict RM strength and function (Enright et al., 1994; McConnell \& Copestake, 1999; Neder et al., 1999), but examination of the contribution of RM strength and endurance to predict exercise performance has been neglected. The moderate relationships evident in the present study indicate the importance of IME in exercise performance. This finding adds to the argument that individuals with 
poor RM function might be limited in their exercise capacity (Weiner et al., 1998; Weiner, Waizman, Magadle, Berar-Yanay, \& Pelled, 1999).

\section{Conclusion}

This study established the fact that active men and women age 50-79 years have significantly greater RM strength and endurance than their nonactive counterparts. In addition, the active individuals who participate in habitual exercise displayed higher predicted $\mathrm{VO}_{2 \max }$ scores, based on a $1.6-\mathrm{km}$-walk test. These results show that respiratory capacity can be maintained with the performance of regular physical activity throughout the older years, presumably allowing a greater quality of life to be maintained. We conclude that the performance of three exercise sessions per week appears adequate to maintain RM function. Further research focusing on the use of specific RM training with older adults is therefore required, in particular with those who are unable to perform regular exercise at the intensity required to elicit a training response.

\section{References}

ABS. (2001). Population by age and sex (ABS cat. no. 3235.0-8.55.001). Canberra, Australia: Australian Bureau of Statistics.

Åstrand, I., Åstrand, P.O., Hallback, I., \& Kilbom, A. (1973). Reduction in maximal oxygen uptake with age. Journal of Applied Physiology, 35, 649-654.

Berger, B.G. (1989). The role of physical activity in the life quality of older adults. In W.W. Spirduso \& H.M. Eckert (Eds.), Physical activity and aging (pp. 42-58). Champaign, IL: Human Kinetics.

Boutellier, U., Büchel, R., Kundert, A., \& Spengler, C. (1992). The respiratory system as an exercise limiting factor in normal trained subjects. European Journal of Applied Physiology and Occupational Physiology, 65, 347-353.

Boutellier, U., \& Piwko, P. (1991). The respiratory system as an exercise limiting factor in normal sedentary subjects. European Journal of Applied Physiology and Occupational Physiology, 64, 145-152.

Brown, D.R. (1992). Physical activity, ageing, and psychological well-being: An overview of the research. Canadian Journal of Sport Science, 17, 185-193.

Buskirk, E.R., \& Hodgson, J.L. (1987). Age and aerobic power: The rate of change in men and women. Federation Proceedings, 46, 1824-1829.

Chen, H., \& Kuo, C. (1989). Relationship between respiratory muscle function and age, sex, and other factors. Journal of Applied Physiology, 66, 943-948.

Clanton, T.L., \& Diaz, P.T. (1995). Clinical assessment of the respiratory muscles. Physical Therapy, 75, 983-995.

Clanton, T.L., Dixon, G.F., Drake, J., \& Gadek, J.E. (1987). Effects of swim training on lung volumes and inspiratory muscle conditioning. Journal of Applied Physiology, 62, 39-46.

Enright, P.L., Johnson, L.R., Connett, J.E., Voelker, H., \& Buist, A.S. (1991). Spirometry in the Lung Health Study. 1. Methods and quality control. American Review of Respiratory Disease, 143, 1215-1223. 
Enright, P.L., Kronmal, R.A., Manolio, T.A., Schenker, M.B., \& Hyatt, R.E. (1994). Respiratory muscle strength in the elderly. Correlates and reference values. Cardiovascular Health Study Research Group. American Journal of Respiratory and Critical Care Medicine, 149, 430-438.

Evans, W.J. (1995). What is sarcopenia? Journal of Gerontology A: Biological Science and Medical Science, 50(Spec. No.), 5-8.

Janssens, J.P., Pache, J.C., \& Nicod, L.P. (1999). Physiological changes in respiratory function associated with ageing. European Respiratory Journal, 13, 197-205.

Kline, G.M., Porcari, J.P., Hintermeister, R., Freedson, P.S., Ward, A., McCarron, R.F., et al. (1987). Estimation of $\mathrm{VO}_{2 \max }$ from a one-mile track walk, gender, age and body weight. Medicine and Science in Sports, 19, 253-259.

Lamoureux, E.L., Sparrow, W.A., Murphy, A., \& Newton, R.U. (2002). The relationship between lower body strength and obstructed gait in community-dwelling older adults. Journal of the American Geriatrics Society, 50, 468-473.

Larson, J.L., Covey, M.K., Berry, J., Wirtz, S., Alex, C.G., \& Matsuo, M. (1999). Discontinuous incremental threshold loading test: Measure of respiratory muscle endurance in patients with COPD. Chest, 115, 60-67.

Larson, J.L., \& Kim, M.J. (1987). Reliability of maximal inspiratory pressure. Nursing Research, 36, 317-319.

Martyn, J.B., Moreno, R.H., Pare, P.D., \& Pardy, R.L. (1987). Measurement of inspiratory muscle performance with incremental threshold loading. American Review of Respiratory Disease, 135, 919-923.

McConnell, A.K., \& Copestake, A.J. (1999). Maximum static respiratory pressures in healthy elderly men and women: Issues of reproducibility and interpretation. Respiration, 66, 251-258.

Neder, J.A., Andreoni, S., Lerario, M.C., \& Nery, L.E. (1999). Reference values for lung function tests. II. Maximal respiratory pressures and voluntary ventilation. Brazilian Journal of Medical and Biological Research, 32, 719-727.

O’Hanley, S., Ward, A., Zwiren, L., McCarron, R.F., Ross, J., \& Rippe, J.M. (1987). Validation of a one-mile walk test in 70-79 year olds. Medicine and Science in Sport and Exercise, 19, S28.

Plonczynski, D.J. (2003). Physical activity determinants of older women: What influences activity? Medical-Surgical Nursing Journal, 12, 213-221, 259.

Poulin, M.J., Cunningham, D.A., Paterson, D.H., Kowalchuk, J.M., \& Smith, W.D. (1993). Ventilatory sensitivity to $\mathrm{CO}_{2}$ in hyperoxia and hypoxia in older aged humans. Journal of Applied Physiology, 75, 2209-2216.

Quanjer, P.H., Tammeling, G.J., Cotes, J.E., Pedersen, O.F., Peslin, R., \& Yernoult, J.C. (1993). Lung volumes and forced ventilatory flows: 1993 update. Report Working Party "Standardization lung function tests." European Coal and Steel Community, European Respiratory Society. European Respiratory Journal, 6, 5-40.

Robertson, R.J. (1982). Central signals of perceived exertion during dynamic exercise. Medicine and Science in Sport and Exercise, 14, 390-396.

Robinson, E.P., \& Kjeldgaard, J.M. (1982). Improvement in ventilatory muscle function with running. Journal of Applied Physiology, 52, 1400-1406.

Rohrbach, M., Perret, C., Kayser, B., Boutellier, U., \& Spengler, C.M. (2003). Task failure from inspiratory resistive loaded breathing: A role for inspiratory muscle fatigue? European Journal of Applied Physiology, 90, 405-410. 
Roubenoff, R. (2000). Sarcopenia and its implications for the elderly. European Journal of Clinical Nutrition, 54(Suppl. 3), S40-S47.

Tanaka, H., Desouza, C.A., Jones, P.P., Stevenson, E.T., Davy, K.P., \& Seals, D.R. (1997). Greater rate of decline in maximal aerobic capacity with age in physically active vs. sedentary healthy women. Journal of Applied Physiology, 83, 1947-1953.

Weiner, P., Gross, D., Meiner, Z., Ganem, R., Weiner, M., Zamir, D., \& Rabner, M. (1998). Respiratory muscle training in patients with moderate to severe myasthenia gravis. Canadian Journal of Neurological Science, 25, 236-241.

Weiner, P., Waizman, J., Magadle, R., Berar-Yanay, N., \& Pelled, B. (1999). The effect of specific inspiratory muscle training on the sensation of dyspnea and exercise tolerance in patients with congestive heart failure. Clinical Cardiology, 22, 727-732. 